$$
\text { NACD } 306
$$

$$
\begin{aligned}
& \text { Reprinted from } 7 N-91-C R \\
& \text { N) } S
\end{aligned}
$$

CQ

\title{
SCIENCE LETTERS
}

A model for the thermal and chemical evolution of the Moon's interior: implications for the onset of mare volcanism

P.C. Hess, E.M. Parmentier *

Deparment of Geological Sciences, Brown University, Providence, RJ 02912, USA

Received 9 December 1994; accepted 19 July 1995

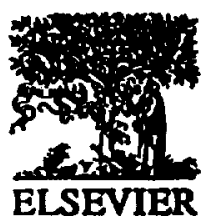


EDITORS
F. ALBAREDE (1.yon)

U.R. CHRISTFNSEN (GötIIngLn)

\section{Australia}

K. LAMBECK (Canberra, A ( T)

Betgium

A.L. BERGER (Louvain-La-Ncuve)

France

C.J. ALLÈGRE (Paris)

Y. BOTTINGA (Paris)

J.P. COGNÉ (Paris)

V. COURTILLOT (Paris)

C. JAUPART (Paris)

H.C. NATAF (Paris)

Germany

H. PALME (Mainz)

S.L. GOLDSTEIN (Mainz)

\section{Dr. F. Albarède}

Ecole Normale Supérieure de Lyon

46 Allée d'Italie,

69364 Lyon Cedex 07, France

Tel.: (33) 72728414

Fax: (33) 72728080

E-mail albarede@geologie.ens-lyon.fr

Dr. U.R. Christensen

Institut für Geophysik

Universität Göttingen

Herzberger Landstrasse 180

37075 Göttingen, Germany

Tel.: (551) 397451

Fax: (551) 397459

E-mail: uro@willi.uni-geophys.gwdg.de
M RASINE:R (la Jolla, (alit.)

( I. AN ( IMURR (Palisades, N.Y.)

ADVISOKY EDITORIAL, IGOARD India

S. KRISHNASWAMI (Almudabal)

Isracel

J.R. (iAT (Rchovol)

Italy

A. LONGINELLI (Tricste)

People's Republic of China

TU (iUANGZHI (Beijing)

United Kingdom

J.C. BRIDEN (Oxford)

R.K. O'NIONS (Cambridge)

\section{EDITORIAL ADDRESSES}

Prof. M. Kastner

Geological Research Division

Scripps Institution of Oceanography

University of California

La Jolla, CA 92093, U.S.A.

Tel.: (619) 534-2065/Fax: (619)534-0784

INTERNET: mkastner@ucsd.edu

Prof. C. Langmuir

Lamont-Doherty Geological Observatory of Columbia University

Palisades, NY 10964-0190, U.S.A.

Tel.: (914) 359-2900/Fax: (914) 365-3183

E-mail: langmuir@ldeo.colombia.edu
N.J. KUSZNIR (Liverpool)

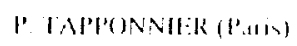

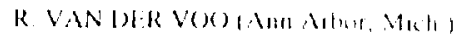

U.SA

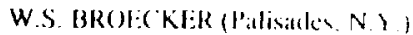

J.M. EDMOND (c'ambridge. Mas)

A.N. HALIII)AY (Ann Arlur. Mich

J.I. KIRSCIVINK ('asadedia. ('alif)

D. LAL (La Jolla, (alif.)

J.G. SCLATER (I a Jolla, (alii)

N.H. SLEEP (Stanford, Calif.)

S. UYEDA (College Station, Tex)
Dr. P. Tapponnier

Institut de Physique du Globe

Mécanique Matériaux Terresıres

4 place Jussieu, Tour 24, $2^{\text {tm }}$ etage.

75230 Paris Cédex 05, France

Tel.: (44) 273905

Fax: (44) 273373

Dr. R. van der Voo

University of Michigan,

Department of Geological Sciences,

1006 C.C. Little Building,

Ann Artor, MI 48109-1063, U.S.A

Tel.: (313) 7641435

Fax: (313) 7634690

\section{PUBLICATION INFORMATION}

Earth and Planetary Science Letters (ISSN 0012-821X). For 1995 volumes 127-135 are scheduled for publication. Subscription prices are available upon request from the publisher. Subscriptions are accepted on a prepaid basis only and are entered on a calendar year basis. Issues are sent by surface mail except to the following countries where air delivery via SAL is ensuręd: Argentina, Australia, Brazil, Canada, Hong Kong, India, Israel, Japan, Malaysia, Mexico, New Zealand, Pakistan, PR China, Singapore, South Africa, South Korea, Taiwan, Thailand, USA. For all other countries airmail rates are available upon request. Claims for missing issues must be made within six months of our publication (mailing) date. Please address alt your requests regarding orders and subscription queries to: Elsevier Science B.V., Journal Department, P.O. Box 211, 1000 AE Amsterdam, The Netherlands. Tel.: 31-20-4853642, fax: 31-20-4853598. U.S. mailing notice: Earth and Planetary Science Letters (ISSN 0012-821X) is published monthly by Elsevier Science B.V., Molenwerf 1, P.O. Box 211, 1000 AE Amsterdam, The Netherlands. The annual subscription price in the U.S.A. is ca. U.S. $\$ 1788$ (USS price valid in North, Central and South Americe only) including air-speed delivery. Second class postage paid at Jamaica, NY 11431, U.S.A. U.S.A. postmasters: Send address changes to Earth and Planetary Science Letters, Publications Expediting, Inc., 200 Meacham Avenue, Elmont, NY 11003, U.S.A.

Advertising information Advertising orders and enquiries may be sent to: Elsevier Science B.V., Advertising Department, P.O. Box 211, 1000 AE Amsterdam, The Netherlands, tel.: +31-20-4853796, fax: +31-20-4853810. Courier shipments to: Molenwerf 1, 1014 AG Amsterdam, The Netherlands. In the UK: T.G. Scott \& Son Ld., attn. Vanessa Bird, Portland House, 21 Nartorough Road, Cosby, Leicestershire, LE9 STA, UK, tel.: +44-0116-2750521/2753333, fax: +44-0116-2750522. In the USA and Canada: Weston Media Associates, attn. Daniel Lipner, P.O. Box 1110, Greens Farms, CT 06436-1110, USA, tel.: +1-203-2612500, fax: +1-203-2610101.

O 1995, EISEVIER SCIENCE B.V. ALL. RIGHTS RESERVED

No part of the publication may be reproduced, stored in s retrieval system or transmitted in ay form or by any means, electronic, mecthanicat, photocopyiag, recording or otherwise, with. out the prior written permission of the publisher, Elacvier Scienoe B.V. Copyright A Permisaions Department, P.O. Box 521, 1000 AM Amsterdam, The Netherlands.

Upon ecceptance of an article by the journel, the mesthor(s) will be asked bo transfer copyright of the article to the publisher. The transfer will easure the widest possible dissemination of

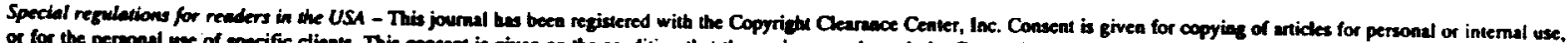

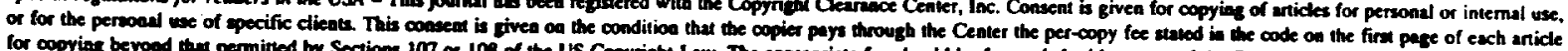

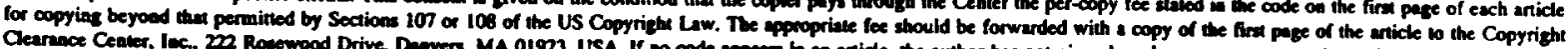

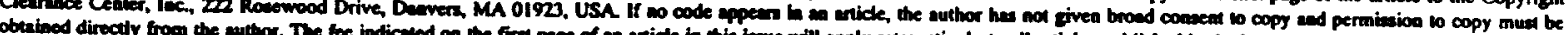

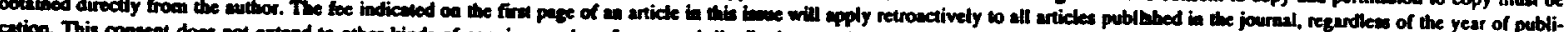

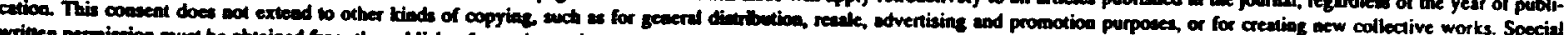

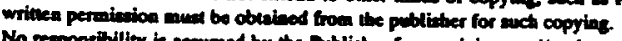

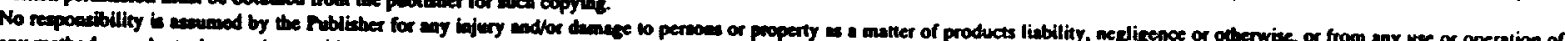
acy methods, products, instruction or ideas containod in the mollerial berein.

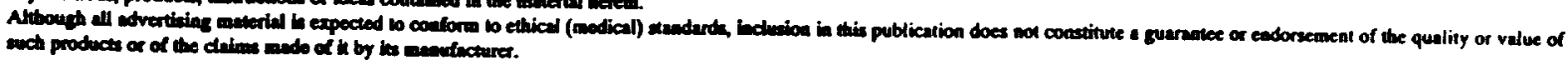

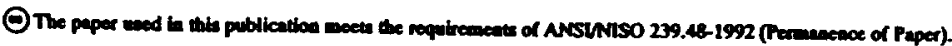

Prinied bi the Nethortand
Abstr

$$
\mathrm{Cr}
$$

magm

crystal

underi

the to:

possib

layer :

overtu

model,

would

the ger

content

a range

gravital

basalt :

importa

1. Intr

This

evoluti

plain $\mathbf{u}$ and po

Inferrec [3], [4],:

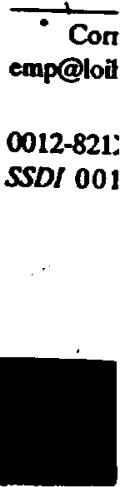


its)

wn Arbor, Mich.)

: iisades, N.Y.)

iridge, Mass.)

n Arbor, Mich.)

ssadena, Calif.)

i)

la, Calif.)

Calif.)

ation, Tex.)

\title{
A model for the thermal and chemical evolution of the Moon's interior: implications for the onset of mare volcanism
}

\author{
P.C. Hess, E.M. Parmentier * \\ Deparment of Geological Sciences, Brown University, Providence, RI 029I2, USA
}

Received 9 December 1994; accepted 19 July 1995

\section{Jlobe}

errestres

$.2^{\text {tme etage, }}$

rance

al Sciences,

:g,

063, U.S.A

iption prices are tar basis. Issues

. Canada, Hong iwan, Thailand, hs of our publi-

B.V., Journal $g$ notice: Earth 211, $1000 \mathrm{AE}$, ntral and South $\because$ Send address i.A.

P.O. Box 211, f 1, 1014 AG Road, Cosby, Weston Media 101.

$\sqrt{12-821 \times 195 / 509.50}$

; o oherwise, with-

te dismemination of

onal or intemal use, page of esch article te io the Copyright on to copy muse be $x$ the year of publitive works. Special

\section{Abstract}

Crystallization of the lunar magma ocean creates a chemically stratified Moon consisting of an anorthositic crust and magma ocean cumulates overlying the primitive lunar interior. Within the magma ocean cumulates the last liquids to crystallize form dense, ilmenite-rich cumulates that contain high concentrations of incompatible radioactive elements. The underlying olivine-orthopyroxene cumulates are also stratified with later crystallized, denser, more Fe-rich compositions at the top. This paper explores the chemical and thermal consequences of an internal evolution model accounting for the possible role of these sources of chemical buoyancy. Rayleigh-Taylor instability causes the dense ilmenite-rich cumulate overturn, radioactive heating cumulates to sink toward the center of the Moon, forming a dense lunar core. After this model, the source region for high-TiO would contain small and the generation of mare basalts, occurs after admixed ilmenite and KREEP. This deep high-pressure melting, as required for content of radioactive elements in the after a reasonable time interval to explain the onset of mare basalt volcanism if the a range of values that might have been and the chemical density gradients above the core are sufficiently high but within gravitational overturn driven by the high basalt sources, and probably a significa density of magma ocean Fe-rich cumulates should concentrate high-TiO mare $_{2}$ important implications for both the theant fraction of radioactive heating, toward the center of the Moon. This will have

\section{Introduction}

This study explores a model for the chemical evolution of the lunar interior that attempts to explain the origin and evolution of lunar magmatism and possibly the existence of a lunar core $[1,2]$. Inferred source depths greater than 400-500 km (cf. $[3],[4],[5])$ as well as the ages $(3.9-3.1 \mathrm{Ga})$ of high-

\footnotetext{
Corresponding author. Fax: (401)863-2058; e-mail: emp@loihi.geo.brown.edu.
}

and low-Ti mare basalt volcanism [6] must reflect evolution do not appear to be explained by previous models for the evolution of the lunar interior. Many previous studies have focussed on geophysical (e.g., $[7,8])$ and tectonic constraints [9-13] on lunar evolution. Among those that specifically address the solidification of the magma ocean (e.g., [14-16]), the study of Solomon and Longhi [14] couples cooling larger scale lunar interior thermal evolution. Accordprocesses of lunar internal evolution. However, these generally accepted characteristics of lunar magmatic and solidification of the magma ocean with the 
ing to their results, magma ocean mafic cumulates, the source of mare basalts required by geochemical constraints, never remelt. Melting of the primitive lunar mantle beneath the magma ocean cumulates, as predicted by their model, would produce magmas but these would not be mare hasalts. The obvious conclusion is that the production of mare basalts must involve factors not included in the Solomon and Longhi model.

We accept, as a working hypothesis, that a large magma ocean, several hundreds of kilometers in thickness, segregated into a plagioclase-rich crust and a complimentary stratified cumulate mantle enriched in $\mathrm{Fe}-\mathrm{Mg}$ minerals (see $[17,18]$ ). The initial stratification of the magma ocean cumulate can only be estimated given the possible complexities associated with the crystallization of a magma body of such extraordinary size (e.g., $[19,20])$. The solidification of this magma ocean could be approximated by models of near-equilibrium crystallization to nearperfect fractional crystallization, or some combination of both processes occurring at different stages. In addition, cooling caused by the rapid transport of quenched melt to the bottom of the magma ocean would induce olivine crystallization, producing a cumulate layer approximating the composition of an olivine-rich bulk Moon [21].

There is clear evidence of fractional crystallization, however, at least in the final stages of solidification of the magma ocean. The formation of the anorthosite-rich crust by $4.5 \mathrm{Ga}$ and the establishment of an ilmenite-bearing cumulate mantle layer by $4.4 \mathrm{Ga}$ [6] require very effective crystal-liquid segregation. Calculations of the rare earth composition of magmas parental to ferroan anorthosites suggest that the plagioclase began to segregate from the magma ocean only after $80-90 \%$ solidification [22]. Thus, fractional crystallization must have been operative at this late stage of magma ocean evolution. An ilmenite-bearing cumulate (IBC) layer would begin to form after about $95 \%$ solidification of the magma ocean [23]. This means that the magma ocean cumulates were stratified with dense FeO-rich phases overlying less dense $\mathrm{MgO}$-rich phases.

This configuration of more dense above less dense mantle is gravitationally unstable. This paper explores the chemical and thermal consequences of an internal evolution model accounting for the possible role of this chemical butrancy. Large scale overturn of the lunar interior would redistribute the components of the mantle with interesting petrological $[2,3,15,24,25]$ and thermal consequences. Since it formed from the last remaining liquid in the magma ocean, the IBC has a high content of incompatible radioactive elements. After overturn, radioactive heating within the IBC heats the overlying mantle, causing it to melt. This heating results in deep melting and, for some parameters, melting occurs after a reasonable time interval to explain the onset of mare basalt volcanism. If the Moon formed by a giant impact into the Earth [26] and consists primarily of material derived from the Earth's mantle, material for a metallic-Fe core may not be present. If there is no metallic core, IBC would sink to the center of the Moon thus providing a simple way to create a relatively dense core. If a metallic core were already present, the IBC would form a layer surrounding the core.

\section{Solidification of the magma ocean: initial chem- ical stratification}

We assume that a magma ocean differentiated into an anorthositic crust and a chenically stratified mantle. The products of this differentiation depend on the depth of the magma ocean, the lunar bulk composition, and the nature and efficiency of the differentiation process. Estimates of magma ocean depths range from $250 \mathrm{~km}$ to the entire Moon [27]. It has been argued that the absence of global scale extensional or compressional features on the lunar surface limit variations in the lunar radius to $\pm 1 \mathrm{~km}$ over the past 3.8 Gyr [9]. Solomon and Chaiken [9] found that for this radius constraint to be satisfied, the contraction due to cooling of the outermost layers of the Moon, which they assumed to be the crystallized product of the magma ocean, must be balanced by radioactive heating of the deeper interior. They argued that this constraint limits magma ocean depths to less than $400 \mathrm{~km}$. Kirk and Stevenson [12] indicated that a $630 \mathrm{~km}$ deep magma ocean can be allowed if contractional cooling of the magma ocean is partially offset by volume changes due to partial melting and chemical differentiation.

These magma ocean thickness contraints pose an 
obstacle to theories of lumar origin that call for all initially molten Moon [10]. But wher factors nol considered in previous models may be important. The downward transport of heat-producing elements, as discussed later, would hasten the cooling of the shallow Moon in the period preceding 3.8 (ia and increase the heating of the deep interior on longer time scales. Both of these effects would allow a larger magma ocean thickness to be consistent with the Solomon and Chaiken constraint.

A magma ocean shallower than $400 \mathrm{~km}$ is problematical from a chemical perspective. Unless the bulk lunar $\mathrm{Al}_{2} \mathrm{O}_{3}$ content is much higher than about $4 \%$ [28-30], a magma ocean thinner than $400 \mathrm{~km}$ cannot provide the $\mathrm{Al}_{2} \mathrm{O}_{3}$ content of the anorthositic crust [18]. Although we cannot rule out an $\mathrm{Al}_{2} \mathrm{O}_{3}$-enriched Moon, we adopt the generally assumed bulk Moon composition.

Recognizing these major uncertainites in determining the thickness of the magma ocean, we consider values ranging from 400 to $800 \mathrm{~km}$. Our standard case is an $800 \mathrm{~km}$ deep magma ocean that creates $60 \mathrm{~km}$ of anorthositic crust (including later additions of $\mathrm{Mg}^{*}$ suite plutons), $30 \mathrm{~km}$ of an ilmenite-enriched cumulate layer beneath the crust, a $710 \mathrm{~km}$ cumulate layer with relatively dense (low $\mathrm{Mg}^{*}$ ) mafic orthopyroxene-olivine layers near the top and less dense (high $\mathrm{Mg}^{*}$ ) olivine-rich cumulate layers near the base (e.g., [31]). This stratigraphic sequence overlies $940 \mathrm{~km}$ of primitive Moon (see [30] for a discussion of chemical models of the Moon).

The ilmenite liquidus in mafic to ultramafic silicate melts occurs for melts containing about 4-5 wt\% $\mathrm{TiO}_{2}$ at temperatures less than $1100^{\circ} \mathrm{C}$ and at low pressures [23]. If we assume a $\mathrm{TiO}_{2}$ content for the magma ocean of $0.2-0.3$ wt\% $\mathrm{TiO}_{2}$ [30] then IBC forms a layer about $30 \mathrm{~km}$ thick. The density of the IBC layer is controlled by the content of ilmenite $\left(\rho \sim 4800 \mathrm{~kg} / \mathrm{m}^{3}\right)$, the $\mathrm{Mg}^{\circ}$ values of pyroxene and the modal abundance of plagioclase $(\rho \sim 2750$ $\mathrm{kg} / \mathrm{m}^{3}$ ). The normative ilmenite content of ilmenite saturated melts at about $1100^{\circ} \mathrm{C}$ is about $10 \mathrm{wt} \%$ $[23,32]$ and the normative content of plagioclase is about $35 \mathrm{wt} \%$. If a significant fraction of the plagioclase floated and was added to the anorthosite crust, then the ilmenite content of the cumulate layer could be as high as $15 \mathrm{wt} \%$, and the thickness of this layer would be about $20 \mathrm{~km}$. We assune very little modal plagioclase in the cumulate layer and a range of reasonable $\mathrm{Mg}_{\mathrm{g}}$. values for the modal pyroxene $\left.\left(\mathrm{Mg}^{\prime}=0.2-1\right) .5\right)$. This range of $\mathrm{Mg}^{*}$ values is consistent with the $\mathrm{Mg}^{*}$ values of the most evolved terroan anorthosites $\left(\mathrm{Mg}^{\circ} \sim \mathbf{0 . 4 0 )}\right.$ which have crystallixed from silicate melts (presumably the magma ocean) that have not reached the ilmenite liquidus $[27,33]$. The density of a cumulate with $15 \%$ ilmenite and $85 \%$ pyroxene $\left(\mathrm{Mg}^{*}=0.30\right)$ is about 3700 $\mathrm{kg} / \mathrm{m}^{3}$

The most primitive mafic minerals in ferroan anorthosite have $\mathrm{Mg}^{*}=0.76$ [24]. If the ferroan anorthosite appeared after $80 \%$ crystallization of the magma ocean [22] then the cumulates lying below the IBC layer must include cumulates with $\mathrm{Mg}^{*} \geq$ 0.76. These cumulates are likely to be largely harzburgites (see [31] for review) with $\rho \sim 3400$ $\mathrm{kg} / \mathrm{m}^{3}$. The first cumulates at the base of the magma ocean cumulate layer are likely to be dunites with $\mathrm{Mg}^{*}$ values determined by the compositon of the magma ocean and the pressure of crystallization [34]. The $\mathbf{M g}^{*}$ values of olivine in equlibrium with a peridotitic magma with $\mathrm{Mg}^{*}>0.80$ at pressures of 3-4 $\mathrm{GPa}$ are $\mathrm{Mg}^{\circ}>0.90$ [34]. These cumulates have $\rho \sim 3300 \mathrm{~kg} / \mathrm{m}^{3}$. A calculated initial density distribution for the cumulate layer consistent with these chemical constraints is given in Fig. 1.

The time needed to solidify the magma ocean is

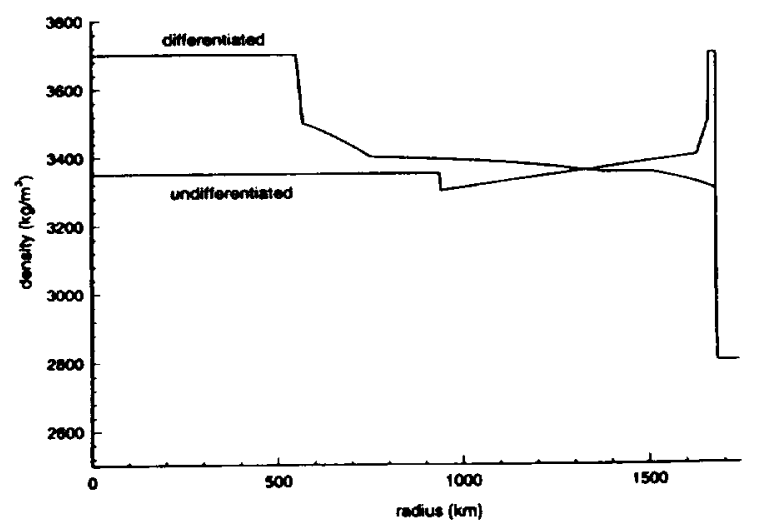

Fig. 1. Intrinsic (chemical) density distribution as a function of radius before ("undifferentiated") and after ("differentiated") overturn. We assume that buoyancy forces in the original unstable configuration result in a rearrangement of mantle layers so that density decreases monotonically with radius. 
largely a function of the thickness and persistence of a solid layer at the surface through which heat is transferred only by conduction. Prior to the formation of a stable solid crust, convective cooling and solidification of the magma ocean will be rapid (cf. $[19,20])$. The rate of solidification would slow dramatically, however, once the magma ocean is blanketed by a stable plagioclase-rich crust [16]. The rate of solidification should be about $100 \mathrm{~km}$ per $10^{8} \mathrm{yr}$ after a stable solid crust of $10 \mathrm{~km}$ or more is a permanent feature of the magma ocean. According to Phinney [22] the anorthosite crust reached this stage after approximately $80 \%$ of the magma ocean had solidified.

Thus, the earliest cumulates, precipitated from a magma ocean undergoing rapid convective cooling, formed within a short time interval of a few million years. The thickness of this cumulate sequence is approximately $700 \mathrm{~km}$ (assuming the anorthosite crust forms only after about $80 \%$ solidification of the magma ocean) for an $800 \mathrm{~km}$ thick magma ocean (e.g., [35]). The last $100 \mathrm{~km}$ of the magma ocean, crystallized over an interval of roughly $100 \mathrm{Myr}$, fractionated into about $40 \mathrm{~km}$ of anorthosite crust (assuming $20 \mathrm{~km}$ of the present-day crust is composed of younger $\mathrm{Mg}$ * suite plutonic rocks [36]) and about $60 \mathrm{~km}$ of $\mathrm{FeO}$-enriched pyroxenite cumulates, the upper $20 \mathrm{~km}$ of which are the IBC layer. As discussed later, the time needed to form the IBC layer and the late-stage pyroxenite cumulates exceeds by one to two orders of magnitude the time scales during which the lowermost olivine-rich cumulate sequence could establish a gravitationally stable stratification. Therefore, the IBC layer formed above a relatively stable platform of $\mathrm{MgO}$-rich, dunite cumulates, which themselves overlay olivine-orthopyroxene cumulates, representing an inverted cumulate stratigraphy.

\section{Large scale overturn of initial unstable stratifi- cation}

The cumulate mantle resulting from solidification of the magma ocean is gravitationally unstable with dense ilmenite-rich cumulates overlying olivine-orthopyroxene cumulates with $\mathrm{Fe} / \mathrm{Mg}$ that decreases with depth. This density stratification will cause large scale overturn of the lunar interior. Consider first a simple idealization that igmores mixing during overturn. Primitive lunar mantle rises to its level of neutral buoyancy in the cumulate layer and most of the dense ilmenite-rich layer sinks to the center, forming a core [15]. The mean density of the IBC $\left(\rho \sim 3700 \mathrm{~kg} / \mathrm{m}^{3}\right.$ with $15 \%$ ilmenite and $85 \%$ clinopyroxene with $\mathrm{Mg}^{*}=0.3$ ) is significantly greater than the density of the lower cumulates and the undifferentiated Moon, assumed to be garnetIherzolite $\left(\rho \sim 3350 \mathrm{~kg} / \mathrm{m}^{3}\right)$. For an $800 \mathrm{~km}$ thick magma ocean, the IBC, after sinking through the mafic cumulates and undifferentiated interior, segregated at the core-mantle boundary as a $200 \mathrm{~km}$ thick layer if a $400 \mathrm{~km}$ radius $\mathrm{Fe}-\mathrm{Ni}-\mathrm{S}$ core already existed or as a sphere of about $550 \mathrm{~km}$ radius, if there was no pre-existing core. An idealized stratigraphy and density distribution after the establishment of a gravitationally stable lunar mantle is shown in Fig. 1. The moment of inertia of the Moon, which only slightly exceeds that for a uniform density sphere (cf.[37]), can be explained by a small ( $\sim 400$ $\mathrm{km}$ radius) metallic core or by a model with no metallic core in which the mantle density increases with depth as implied by the model in Fig. 1. A 400 $\mathrm{km}$ thick magma ocean, rather than $800 \mathrm{~km}$ as assumed in this example, would result in an IBC core radius of about $475 \mathrm{~km}$.

After the overturn the uppermost mantle would probably still contain a thin zone perhaps less than a few kilometers in thickness of incompatible element-rich cumulates crystallized from the last liquids of the magma ocean (which have been termed UrKREEP cumulates; cf. [38]) and whatever fraction of the IBC layer that survived the overtum. These cumulates rest upon olivine-cumulates $\left(\mathrm{Mg}^{*}>0.90\right)$ which, in turn, overlie a $150 \mathrm{~km}$ thick layer derived from the initially undifferentiated interior. This layer was displaced upward by the sinking IBC. The layer corresponding to the undifferentiated interior overlies a cumulate section which is initially olivine-rich but grades with depth to an olivine-orthopyroxene assemblage. The olivine-pyroxene assemblage continues almost to the IBC layer-mantle boundary.

The true stratigraphy of the Moon is bound to be more complex since at least some mixing will occur. Small masses of IBC, for example, have small settling velocities and may remain trapped and dis- 
-onsider - during level of most of center, the IBC id $85 \%$ ificantly ates and garnetim thick ugh the $\therefore$, segreim thick already adius, if 1 stratiglishment ;hown in $n$, which density

I $(\sim 400$ with no increases 1. A 400

I $\mathrm{km}$ as an IBC

le would "ss than a impatible $e$ last liqin termed $r$ fraction r. These $>0.90)$ sr derived This layer The layer rior overivine-rich spyroxene lage conndary. und to be vill occur. small setand dis- persed throughout the mantle. Sinking and rising diapirs may entrain and convectively mix with portions of the mantle through which they pass $[3,39]$. The sinking and associated mixing of cumulates represents a process by which KREEP-rich cumulates and IBC could be dispersed throughout the mantle (see also $[19,40]$ ). Such mixing would reduce the density stratification shown in Fig. I, which assumes no mixing at all.

The roughly $550 \mathrm{~km}$ radius $\mathrm{IBC}$ core contains about 15 wt\% ilmenite. The IBC cumulates should also be enriched in highly incompatible elements, especially the heat-producing elements. The IBC were derived from melts which contained about 20 times lunar abundances of heat-producing elements because the melts parental to IBC are liquids obtained after $95 \%$ crystallization of the magma ocean. We assume that rising plagioclase cumulates are impoverished in these elements, so that the complementary mantle contained about $\mathbf{3 0}$ times lunar abundances. Some fraction of these heat-producing elements will be carried to the lunar IBC core. We assume that the heat-producing elements range from 5 to 10 times bulk lunar abundances in the analysis that follows.

\subsection{Temporal and spatial scales for overturn of initial chemical stratification}

Rayleigh-Taylor instability will take two forms, large scale overturn of the interior driven by the high density of the ilmenite-rich cumulate layer and internal overturn of the magma ocean cumulates beneath the ilmenite-rich cumulate layer. The magma ocean cumulates that form below the IBC layer are internally stratified with denser Fe-rich cumulates overlying earlier formed $\mathrm{Mg}$-rich cumulates. Most of these cumulates are less dense than the primitive interior and so do not promote large scale overturn of the lunar interior. The time scale for internal overturn of the cumulates can be estimated from the growth rate of Rayleigh-Taylor instability in a constant viscosity fluid layer in which the fluid density varies linearly with depth:

$t=\frac{4 \pi^{2} \mu}{\Delta \rho g d}$ and

$\lambda=2 d$

where $d$ is the depth of the layer, $J /$ is the density difference between the top and hollom, and $\mu$ is the viscosity. For $\Delta \rho=.350 \mathrm{~kg} / \mathrm{m}^{\prime}, \mu=10^{19} \mathrm{~Pa} s$ and $d=7 \times 10^{5} \mathrm{~m}$, the chatracteristic time is roughly 0.03 Myr. We argucd previously that the crystallization of the last $100 \mathrm{~km}$ of the magma ocean would slow dramatically once an anorthosite crust was stabilized. Estimates of the crystallization time are on the order of $100 \mathrm{Myr}$. It appears, therefore, that the lower cumulate pilc will have reached gravitational equilibrium before most of the IBC has formed

Large scale gravitational instabilty will be driven primarily by the high density of the IBC layer. First, consider the simple, but probably unrealistic, case in which the IBC solidifies rapidly compared to the time scale of differentiation. The time scale for the sinking of the IBC layer to the center of the Moon can be controlled by the time for diapirs to form by Rayleigh-Taylor instability or by the time for the resulting diapirs to sink through the lunar mantle. This time scale will be determined by the wavelength of instability and the corresponding size of the diapirs.

An estimate of the time needed for RayleighTaylor instablity of the ilmenite-rich cumulate layer to develop is (e.g., [52]):

$t=\frac{6.5 \mu_{2}^{2 / 3} \mu_{1}^{1 / 3}}{\Delta \rho g h}$

with a wavelength of instability:

$\lambda=2.9 h\left(\frac{\mu_{2}}{\mu_{1}}\right)^{1 / 3}$

where $\mu_{1} \ll \mu_{2}$. In these expressions $\mu_{1}$ and $\mu_{2}$ are the viscosity of the IBC and underlying cumulates, respectively ( $10^{19} \mathrm{~Pa} s$ for mantle silicates near their melting temperature would be a reasonable minimum value), $\Delta \rho\left(0.35 \times 10^{3} \mathrm{~kg} / \mathrm{m}^{3}\right)$ is the density difference between them, $h$ is the layer thickness $(\sim 20$ $\mathrm{km}$ ), and $g$ is the acceleration of gravity at the appropriate depth. Given the uncertainty in a number of these parameters, particularly the viscosities, this time ranges from $10^{4}$ to $10^{5} \mathrm{yr}$. The wavelength of instability is sensitive to the viscosity of the ilmenite-rich cumulate layer. If this viscosity were an 
order of magnitude less than that of underlying cumulates, $\mu_{1} / \mu_{2} \approx 10$ ', the wavelength of instability would be about $6 \mathrm{~h}$ or $120 \mathrm{~km}$. Equating the layer volume in one wavelength of instability, $\lambda^{2} h$, to that of the resulting diapir gives a diapir diameter of about $80 \mathrm{~km}$. About 2000 such diapirs would form. Such a small scale of instability could result in some mixing during the differentiation. This number of diapirs varies inversely with $\lambda^{2}$ and therefore the number of diapirs is proportional to $\left(\mu_{1} / \mu_{2}\right)^{2 / 3}$. For $\mu_{1} / \mu_{2} \approx 10^{-5}$, only a single diapir would form. This larger scale of instability would result in less mixing during the differentiation. It is interesting to hypothesize that the lunar center of figure-center of mass offset and corresponding crustal asymmetry (cf. [37]) might be indicative of such a large scale instability.

The time required for a diapir to sink is estimated using the Stokes settling velocity of a fluid sphere with viscosity $\mu_{1}$ settling in a fluid of viscosity $\mu_{2}$ (cf. [41]):

$V=\frac{1}{3} \frac{\Delta \rho g a^{2}}{\mu_{2}}\left(\frac{\mu_{2}+\mu_{1}}{\mu_{2}+\frac{3}{2} \mu_{1}}\right)$

where $a$ is the diapir radius $4 \pi a^{3} / 3=\lambda^{2} h$. The sinking time over a distance comparable to the radius of the Moon ( $1740 \mathrm{~km}$; see Fig. 1) for the cases with $\mu_{1} / \mu_{2} \approx 10^{-1}$ and $10^{-5}$ cited above with $\mu_{2}$ $=10^{19} \mathrm{~Pa} s$ are $2 \mathrm{Myr}$ and $3 \times 10^{-2} \mathrm{Myr}$, respectively. Thus for $\mu_{1} / \mu_{2} \approx 10^{-1}$ the differentiation time is controlled by the sinking of small diapirs but the opposite is true for $\mu_{1} / \mu_{2} \approx 10^{-5}$. Good estimates of the relative viscosities are thus important for understanding the rate controlling step in the differentiation. Whether the IBC layer is much less viscous or only slightly less viscous than the underlying mantle depends strongly on the melt fraction present as diapir(s) begin to form and on how this melt is distributed on the grain-size scale. If melt wets grain faces forming a thin, low shear strength film, a small melt fraction may greatly reduce the viscosity. Alternatively, if melt does not wet grain faces, small amounts of melt along grain edges and at grain triple junctions will only modestly reduce the viscosity (cf. [42D. Experimental evidence on the degree to which melt of the appropriate composition wets grain boundaries of coexisting minerals is not yet available.
It is important to recognize that the differentiation process will be much more complex than these simple estimates appear to imply. Diapirs will develop while the layer is still solidifying, rather than after solidification is complete as assumed above. The scale of diapirs that develop can be estimated by equating the thickening rate of the solidified IBC layer $\dot{h} / h$ with the rate of diapir formation as determined by the reciprocal of the Rayleigh-Taylor growth time given above. This gives an estimate of the steady-state layer thickness as solidification proceeds:

$h \approx\left(\frac{6.5 \mu_{1}^{1 / 3} \mu_{2}^{2 / 3} h}{\Delta \rho g}\right)^{1 / 2}$

where $\Delta \rho$ is density difference between the layer and underling cumulates and other symbols have the same meaning as above. For this layer thickness an estimate of the wavelength of instability and the resulting diapir size also follow from expressions given above. For $\mu_{1} / \mu_{2} \approx 10^{-1}$ and a solidification rate of $0.1 \mathrm{~km} / \mathrm{Myr}$, the estimated layer thickness, wavelength of instability, and diapir diameter are 0.5 $\mathrm{km}, 3 \mathrm{~km}$, and $2 \mathrm{~km}$, respectively. For $\mu_{1} / \mu_{2} \approx 10^{-5}$ and the same solidification rate, the corresponding values are $0.1 \mathrm{~km}, 13 \mathrm{~km}$, and $4 \mathrm{~km}$.

The rate of solidification of the layer appears to be an important parameter. The Solomon and Longhi [14] model predicts that the residual layer remains partly liquid for $350 \mathrm{Myr}$ after crystallization of the majority of the magma ocean. This gives a solidification rate of about $0.05 \mathrm{~km} / \mathrm{Myr}$. In their model solid mantle is present above the residual liquid layer. Sinking of this gravitationally unstable layer through the residual layer approximately halves the distance through which heat must be conducted to reach the surface (see [14], fig. 8). The solidification time of the layer by steady state heat conduction is proportional to the layer depth (the distance over which heat must be conducted) and so would be reduced by a factor of about 2 . For transient heat conduction the cooling time is proportional to the square of the depth and so would be reduced by a factor of 4 . Diapir size is proportional to $\sqrt{\dot{h}}$ so that even with solidification rate $2-4$ times larger, the diapir sizes will be small.

Thus, as the IBC layer crystallizes, small diapirs 
:ntiation ese simdevelop an after ive. The rated by ied IBC as deterh-Taylor imate of tion pro-

the layer have the kness an and the rressions lification nickness, :r are 0.5 ${ }_{2} \approx 10^{-5}$ sponding

ppears to d Longhi remains on of the ;olidificadel solid id layer. I through : distance reach the n time of $s$ propor'er which :duced by uction the re of the :tor of 4. zven with apir sizes all diapirs will continually form and sink into the underlying cumulates generating a layer that is a mixture of IBC and earlier cumulates. The thickness of this mixed layer can be estimated as the product of the solidification time and the diapir settling velocity. For a 20 $\mathrm{km}$ thick IBC layer solidifying at $0.1 \mathrm{~km} / \mathrm{Myr}$ (solidification time $=2(0) \mathrm{Myr})$, a $2 \mathrm{~km}$ diameter diapir should sink a maximum distance of $80 \mathrm{~km}$. The IBC layer is thus diluted by a factor of 4 . Since the settling velocity is proportional to $h$ and the solidification time is inversely proportional to $\dot{h}$, the mixed layer thickness is actually independent of the solidification rate. The size of IBC diapirs in this mixed layer is, however, dependent on this rate.

This thicker mixed layer will generate global scale instability as initially described above for the IBC layer alone. The time scale of instability, which depends only the product of $\Delta \rho$ and layer thickness, remains the same as that estimated previously. The wavelengths of instability will be larger by about a factor of 4 corresponding to the greater thickness of the mixed layer. However, this mixed layer itself will form diapirs on time scales shorter than the time for the whole layer to form. The differentation process is clearly complex, but these simple considerations suggest that differentiation will occur quickly and a dilution of IBC by about a factor of 4 .

How heat sources will be distributed in this sinking IBC-cumulate mixture is more difficult to assess. If heat-producing elements were perfectly incompatibile, they would be continually concentrated into whatever liquid remained, until that liquid became saturated in these elements. Sinking solid will, however, carry with it some buoyant intragranular liquid. Adiabatic compression will freeze this liquid increasing its density and allowing it to continue sinking. How much liquid can be carried downward in this way depends on the rate of melt migration and/or the rate of compaction of the solid. Given the obvious complexities of the differentiation process, we simply consider a range of heat-production values in the IBC core from 5 to 10 times bulk Moon values.

\subsection{Internal evolution after large scale overturn}

The initial chemical density stratification of the lunar mantle after overturn is large and gravitionally stable $\left(\Delta \rho \approx 200 \mathrm{~kg} / \mathrm{m}^{3}\right.$; see Fig. 1). For a typical coefficient of thermal expansion $\left(3 \times 10^{5} / K\right)$, the superadiabatic temperature difference between the top and bottom of the lunar mantie would have to exceed $2000^{\circ} \mathrm{C}$ for large scale thermally-driven manthe convection to disrupt this initial stratification. Even assuming very low initial temperature in the primitive lunar interior beneath the magma ocean, known crystallization temperatures of the magma ocean would not allow an initial temperature difference this large. Thermally-driven convection in the interior will begin in mixed layers near the top of the mantle and at the core-mantle boundary with thicknesses determined by the chemical density difference that can be penetrated by thermally buoyant mantle. The following analysis treats the development of such a layer adjacent to the core-mantle boundary assuming that the effect of the complementary layer expected to develop at the top of the mantle has not yet reached a sufficient depth to be important.

With a concentration of incompatible heat-producing elements 5-10 times that of the bulk Moon, the ilmenite core heats the overlying olivine-orthopyroxene cumulates. A thermal boundary layer at the core-mantle boundary that thickens by conduction becomes unstable when the Rayleigh number based on the boundary layer thickness exceeds a critical value:

$R a_{\text {cril }}=\frac{\rho \alpha g\left(T_{\mathrm{c}}-T_{\mathrm{m}}\right) \delta^{3}}{\mu \kappa} \approx 10^{3}$

generating plumes that rise into the overlying chemically layered mantle. Here $T_{\mathrm{c}}$ and $T_{\mathrm{m}}$ are temperatures at the core mantle boundary and in the overlying mantle, $\alpha$ is the coefficient of thermal expansion $\left(3 \times 10^{-5} \mathrm{~K}^{-1}\right), \kappa$ is the thermal diffusivity $\left(10^{-6}\right.$ $\mathrm{m}^{2} / \mathrm{s}$ ), and $g$ is the gravity at a depth of $1200 \mathrm{~km}$. This instability criterion assumes that the chemical density difference over the thickness of the thermal boundary layer is negligible compared to the thermal density difference. The time $\tau$ for the thermal boundary layer to grow conductively to thickness $\delta$ at which it becomes unstable is:

$\tau=\frac{\delta^{2}}{2 \kappa}$

Repeated growth and instability of the boundary layer forms thermals that rise into the overlying 
mantle. Taking $\left(T_{\mathrm{c}}+T_{\mathrm{m}}\right) / 2$ as an estimate of average temperature of material in the thermal boundary layer, the heat flux $(q)$ into the overlying mantle is simply the product of the amount of heat added each time the boundary layer becomes unstable $\rho c_{p}\left(T_{c}-\right.$ $\left.T_{m}\right) \delta / 2$ and the frequency of instability $1 / \tau$ :

$q=\frac{\rho c_{p}\left(T_{c}-T_{m}\right) \delta}{2 \tau}$

where $c_{p}(1 \mathrm{~kJ} / \mathrm{kg} \mathrm{K})$ is the heat capacity.

Several simple but reasonable assumptions are made to treat the dynamics of thermal plumes rising in chemically stratified surroundings. (1) Plumes
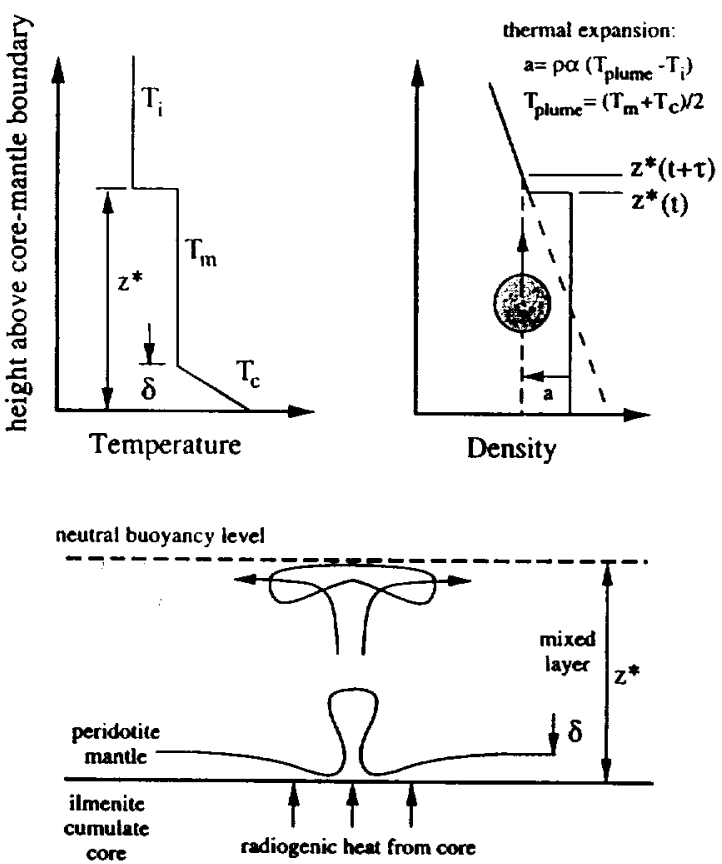

Fig. 2. Important features of the thermal evolution model of a chemically stratified lunar mantle heated from below by radioactivity in the ilmenite core. The bottom diagram illustrates that plumes form from an unstable thermal boundary layer at the base of the mantle. Plumes rise adiabatically to a height at which the combined themal and chemical buoyancy in the plume and in overlying mantle are equal. The rise of plumes is assumed to create a thermally and chemically well-mixed layer. At any time $t$, plumes, which rise through the well-mixed layer of thickness $z^{*}(t)$, penetrate the overlying mantle to a height $z^{*}(t+\tau)$, where $T$ is the time required to conductively form an unstable thermal boundary layer. The mantle is taken to have an initial temperature $T_{i}$ with an intrinsic (chemical) density that decreases linearly with height, as estimated from Fig. 1.

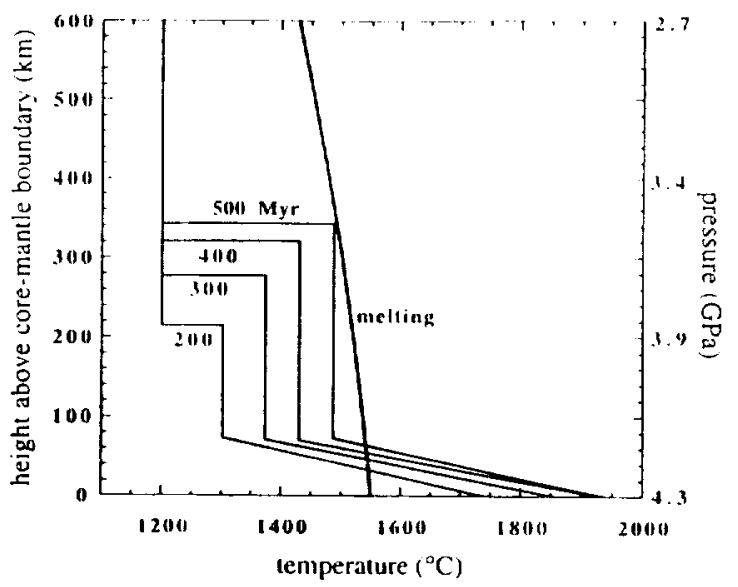

Fig. 3. Calculated thermal structure as a function of time for a core radioactivity 10 times bulk earth, a chemical density stratification above the core-mantle boundary of $0.9 \times 10^{-7} / \mathrm{km}$, a $10^{19}$ $\mathrm{Pa} s$ mantle viscosity, and an initial core and mantle temperature of $1200^{\circ} \mathrm{C}$. This corresponds to parameters in the third row of Table 1 and the results labelled (3) in Fig. 4.

formed at the core-mantle boundary (CMB) rise into intrinsically (chemically) less dense but colder mantle. Plumes with the average temperature and composition in the marginally stable thermal boundary layer rise to a height above the CMB where the positive thermal and negative chemical buoyancy balance. (2) Plumes cause overturn and mixing of the mantle through which they rise, thus thermally and chemically homogenizing a mantle layer equal to the plume rise height. Thus, as shown in Fig. 2, the mixed layer above the thermal boundary layer has a uniform temperature $T_{m}$. The initial intrinsic chemical density stratification is taken to be a simple linear function of height above the CMB. With the assumption of complete mixing, the intrinsic density in the mixed layer is just the average of the initial, pre-existing variation over the layer thickness, as shown in Fig. 2. The density of plumes and of the mantle above the mixed layer are given by the intrinsic density reduced by thermal expansion, as shown in Fig. 2. As the temperature $T_{m}$ increases with time, the mixed layer thickness also increases.

The evolution of the mixed layer thickness $z$ * and the mean temperature $T_{\mathrm{m}}$ within it follow from a simple energy balance: the change of thermal energy over a small increment of time is a consequence of heat added by thermal boundary layer instability and 


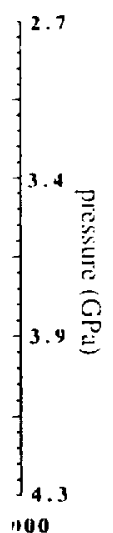

me for a y stratifim, a $10^{19}$ perature $\checkmark$ row of

ise into I mancompoundary ere the loyancy $\mathrm{g}$ of the Illy and إينئي 2 , the :r has a chemie linear issump$y$ in the pre-exlown in mantle intrinsic rown in th time,

less $z^{\circ}$ , from a i energy rence of lity and entrainment of cooler overlying mantle into the mixed layer. In a spherical geometry, where $R$ is the radius of the $\mathrm{CMB}$, this energy balance can be written:

$$
\begin{aligned}
& \frac{1}{3 R^{2}} \frac{\mathrm{d}}{\mathrm{d} t}\left\{\rho c_{\mathrm{p}} T_{\mathrm{m}}\left[\left(R+z^{*}\right)^{3}-R^{3}\right]\right\} \\
& \quad=q-\rho c_{\mathrm{p}}\left(T_{\mathrm{m}}-T_{\mathrm{i}}\right) \frac{\mathrm{d} z}{\mathrm{~d} t}
\end{aligned}
$$

The core temperature is similarly determined by balancing secular and radioactive heating with the rate of heat loss to the overlying mantle. Since substantial melting of the ilmenite-rich core and the thermal boundary layer occurs, the heat of melting $(600 \mathrm{~kJ} / \mathrm{kg} \mathrm{K})$ is also included.

We explore predictions of this model for a range of mantle viscosity $\left(10^{19}-10^{20} \mathrm{~Pa} \mathrm{~s}\right)$ and core radioactivity values (5-10 times bulk earth) with an initial core and mantle temperature of $1200^{\circ} \mathrm{C}$. This initial temperature of the core and the mantle just above it is estimated by taking the solidification temperature of the IBC layer to be $1100^{\circ} \mathrm{C}$ and by including the increase in temperature accompanying the adiabatic compression of the sinking IBC diapir(s). Just above the IBC core in Fig. 1, the density changes by about $1 \%$ over a height of 100 $\mathrm{km}$. However, if some mixing occured during overturn, the compositional gradient would be reduced. We therefore consider cases with $0.9 \%, 0.6 \%$, and $0.3 \%$, density changes over $100 \mathrm{~km}$. Table 1 summarizes the range of model parameters the we have
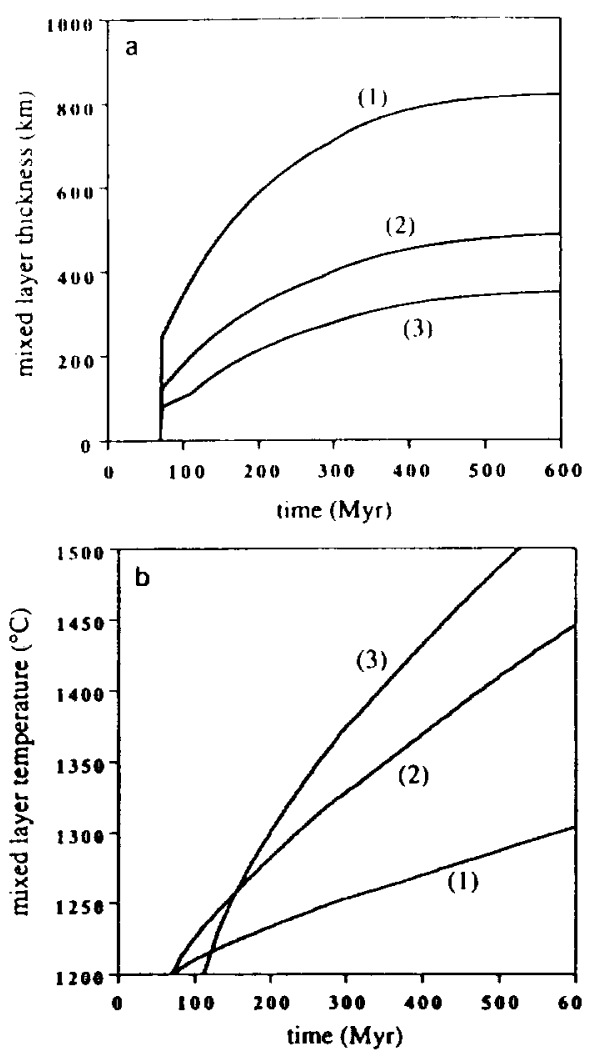

Fig. 4. Mixed layer thickness and temperature as functions of time for a range of chemical density gradients corresponding to rows (1), (2), and (3) in Table 1 . The case with the highest chemical density gradient (3) corresponds at a given time to the thinnest mixed layer and the highest temperature, since nearly the same amount of heat has been added to a thinner layer.

Table 1

Selected model parameters and results

$\begin{array}{cccccccc}\text { heating } & \begin{array}{r}\text { viscosity } \\ (\mathrm{Pa}-\mathrm{sec})\end{array} & \begin{array}{c}\text { core } \\ \text { radius } \\ (\mathrm{km})\end{array} & \begin{array}{c}\text { compositional density } \\ \text { gradient } \\ \left(\mathrm{km}^{-1}\right)\end{array} & \begin{array}{c}\text { time to } \\ \text { melting } \\ (\mathrm{Myr})\end{array} & \begin{array}{c}\text { melting } \\ \text { depth } \\ (\mathrm{km})\end{array} & \begin{array}{c}\text { melting } \\ \text { temperature } \\ \left({ }^{\circ} \mathrm{C}\right)\end{array} & \begin{array}{c}\text { melting } \\ \text { pressure } \\ (\mathrm{GPa})\end{array} \\ 10 . & 10^{19} & 550 . & 0.3 \times 10^{-7} & 996 . & 336 . & 1365 . & 1.84 \\ 10 . & 10^{19} & 550 . & 0.6 \times 10^{-7} & 636 . & 760 . & 1458 . & 3.08 \\ 10 . & 10^{19} & 550 . & 0.9 \times 10^{-7} & 507 . & 807 . & 1491 . & 3.54 \\ 5 . & 10^{19} & 550 . & 0.3 \times 10^{-7} & 1965 . & 522 . & 1421 . & 2.59 \\ 10 . & 10^{20} & 550 . & 0.9 \times 10^{-7} & 735 . & 664 . & 1459 . & 3.09 \\ 10 . & 10^{19} & 475 . & 0.6 \times 10^{-7} & 774 . & 810 . & 1474 . & 3.42 \\ 10 . & 10^{19} & 475 . & 0.9 \times 10^{-7} & 642 . & 948 . & 1502 . & 3.79\end{array}$


examined. The peridotite soliclus is taken to be that of an ilmenite-bearing harzburgite [3]. Fig. 3 shows calculated temperature distributions for one of the models. The temperature distribution within the thermal boundary layer, approximated as a simple lincar variation, is shown just prior to instability at each of the times shown. Fig. 4 shows the variation in mixed layer temperature and thickness with time for several of the models listed in Table 1 . These are further discussed below

\section{Discussion}

In all of these models melting in the mantle begins within the thermal boundary layer just above the core-mantle boundary. Consider, for example, the thermal evolution of the mantle for model (3) (Table 1) with a heat source of 10 times bulk earth values and a density gradient of $-0.9 \%$ per $100 \mathrm{~km}$ in height above the core-mantle boundary. The temperature profile of the mantle above the core-mantle boundary $400 \mathrm{Myr}$ after the overturn of the lunar mantle and core formation consists of a $320 \mathrm{~km}$ well-mixed mantle layer with a temperature of $1425^{\circ} \mathrm{C}$, a temperature still well below the mantle solidus at that depth (Fig. 3). However, the roughly $70 \mathrm{~km}$ thick, thermal boundary layer is partially molten. Melting in the thermal boundary layer may slightly increase or decrease the density of the partially molten mantle, given estimates of melt and solid densities at these conditions [5]. The effect of melting on buoyancy is likely to be small compared to the effect of thermal expansion. We therefore have neglected melt buoyancy in the models described above. The possible effect of the presence of melt in the lunar core will be considered later.

The thermal boundary layer is thermally buoyant and becomes unstable, mixing both thermally and chemically with the overlying mantle. The mass of the thermal boundary is cooled to the mean temperature of the mixed mantle. With the temperature of the mixed layer below the local solidus, whatever melt is transported to the mixed layer from the thermal boundary layer crystallizes and releases latent heat in the mixed mantle layer. The temperatures depicted in Fig. 3 include the thermal contribution of this latent heat.
Within 500 Myr of core formation, the thickness of the mixed layer has reached over $340 \mathrm{~km}$, and more significantly, the temperature at the top of the mixed layer has exceeded the local solidus at a depth corresponding to a pressure of $3.5 \mathrm{GPa}$. The timing and depth at which melting begins in the mixed layer is dependent on several of the model parameters. Fig. 4a and $b$ describes the time evolution of mixedlayer temperature and thickness, respectively, for density gradients of $-0.3,-0.6$ and $-0.9 \% / 100$ $\mathrm{km}$ in height above the core-mantle boundary. The coolest and thickest mixed layer occurs for the mantle with the smallest density gradient. Greater thickness for smaller density stratification is a consequence of the greater rise height of thermal plumes in a smaller adverse compositional density gradient. Lower temperature is a consequence of adding heat from repeated instabiltiy of the thermal boundary layer to the larger mass of mantle in the mixed layer. Based on the results of Fig. 4, the mixed mantle with a low compositional density gradient at a given time is thicker but cooler than that with a high compositional density gradient. The stable chemical stratification acts to confine heat to a thinner layer. As a consequence, melting in the mixed layer occurs at lower pressure, lower temperature and more than 400 Myr later for the low density gradient than in the high density gradient (Table 1).

The thermal evolution and subsequent melting of the mixed layer also depends on the concentration of heat-producing elements in the core. Reducing the radioactivity to 5 times bulk earth values has dramatic consequences. The solidus at the top of the mixed layer is reached but only after a considerable time interval 1 Gyr later than the case for 10 times core radioactivities (Table 1). Similarly, increasing the mantle viscosity from $10^{19}$ to $10^{20} \mathrm{~Pa}$ s increases the time for melting at the top of the mixed layer by about 200 Myr. Melt is generated at slightly lower temperatures and somewhat shallower (compare (3) and (5) in Table 1).

We already noted that the temperatures obtained at the bottom of the thermal boundary and in the core exceed the solidus soon after the overturn. Assuming that the mantle is a harzburgite or perhaps an olivine-bearing orthopyroxenite as seems likely, the melt fraction can approach $100 \%$. The temperature of the forsterite-enstatite $\left(\mathrm{Mg}^{*}=1.0\right)$ cotectic 
akness

II. and

of the

depth

liming

:d layer

meters.

mixed-

:ly, for

$\% / 100$

ry. The

ie man-

is thick-

conse-

plumes

radient.

ing heat

sundary

-d layer.

tle with

en time

omposi-

stratifi-

er. As a

ccurs at

than 400

$n$ in the

elting of

rration of

rcing the

has dra-

ip of the

siderable

10 times

ncreasing

increases

I layer by

tly lower

npare (3)

obtained nd in the overturn. « perhaps ms likely, : tempera-

) cotectic is about $19000^{\circ} \mathrm{C}$ at 4 (iPa; the congruent melting points for enstatite and forsterite are about $1920^{\circ} \mathrm{C}$ and $2100^{\circ} \mathrm{C}$ at these pressures [4.3]. The $\mathrm{Mg}^{\circ}$ values of these cumulates is assumed to be 0.80 . The licyuidus temperature of olivine is depressed by $3^{\circ} \mathrm{C} / \mathrm{Mg}^{*}$-number or by about $60^{\circ} \mathrm{C}$ for an $\mathrm{Mg}^{*}=$ 0.80 (see [44], fig. 16.2). Thus, the liquidus temperatures of olivine and enstatite $\left(\mathrm{Mg}^{\circ}=0.80\right)$ is roughly $2040^{\circ} \mathrm{C}$ and $1860^{\circ} \mathrm{C}$, respectively, at these pressures. Thus for the temperatures shown in Fig. 3, the lower portions of the thermal boundary layer are totally molten for pyroxene-rich lithologies but only partially molten for olivine-rich cumulates.

The liquidus temperature for the lunar core is even lower because the $\mathrm{Mg}^{*}$ values are lower. If this analysis is correct, the lunar core is totally molten about 400-500 Myr after core formation for 10 times bulk earth radioactivities. It is interesting to note that the high apparent Love number of the Moon can be explained by a partially molten central region with $800 \mathrm{~km}$ radius that persists to the present [13]. The concentration of heat sources and low melting temperature materials toward the center of the Moon would make it easier to explain a currently molten lunar core.

What role might melting of the lunar IBC core play in the thermal and chemical evolution of the lower mantle? In our model, the lunar core contains about $15 \mathrm{wt} \%$ ilmenite and $85 \mathrm{wt} \%$ pyroxene \pm plagioclase. The density of the molten core can only be estimated given the large extrapolations needed to obtain the appropriate thermal expansions and compressibilities. Moreover, reasonably modest changes in the $\mathrm{TiO}_{2}, \mathrm{Mg}^{*}$ number and the $\mathrm{SiO}_{2}$ content can have significant effects on the calculated density. For mare-like melts with $8 \% \mathrm{TiO}_{2}$ (equivalent to $15 \%$ normative ilmentite), the results of Delano [5] suggest that the density of the molten core is about $3400 \pm 100 \mathrm{~kg} / \mathrm{m}^{3}$.

In comparison, the density of a partially or even fully molten mantle in the thermal boundary layer is much less. We assume that the mantle in the thermal boundary layer is largely low $\mathrm{CaO}$-pyroxene $\left(\mathrm{Mg}^{*}\right.$ $\approx 0.80$ ) \pm olivine and minor ilmenite. The density of molten low $\mathrm{CaO}$-pyroxene at $1900^{\circ} \mathrm{C}$ is about 2700 $\mathrm{kg} / \mathrm{m}^{3}$ [45], whereas any unmelted olivine has a density of less than $3300 \mathrm{~kg} / \mathrm{m}^{3}$ at these temperatures [5]. The density of the melt corrected to 4.5
GPa [5] is roughly 3000$) \mathrm{kg} / \mathrm{m}^{3}$. It follows that the partially to totally molten thermal boundary layer is gravitationally stable relative to the molten core. The two layers may not remain isolated from each other, however. Core material may be entrained as the thermal boundary layer becomes unstable and rises in the overlying cumulates; alternatively convection in the core may entrain melted mantle in the thermal boundary layer, croding the base of the mantle. These processes may be important but have not been incorporated in the model described above and are not considered further in this paper. Both effects would enhance the rate of heat transfer into the base of the mantle from the core.

If our lower estimates for the densities of the molten core are correct, it may be unstable relatively to the overlying mantle. A molten core with $\rho<3400$ $\mathrm{kg} / \mathrm{m}^{3}$ is capable of becoming unstable relatively to the more iron-rich pyroxene-rich cumulates (Fig. 1). If so, core material, once it melts, might rise to form a layer displaced from the center of the Moon, at its height of neutral buoyancy in the overlying cumulate mantle. It also is possible that the core material might mix with the overlying mantle to a limited extent. These possibilities, although interesting, are not pursued further in this paper.

\subsection{Mare basalt genesis}

An important constraint on mare petrogenesis provided by experimental phase relations shows that pristine mare glasses are multiply saturated with olivine and orthopyroxene at pressures between $2.0-$ $2.5 \mathrm{GPa}$ but have only olivine on the liquidus at lower pressures $[4,46]$. If they are primary magmas and if both olivine and orthopyroxene were left in the source, the mare glasses must have been derived from pressures of about 2.0-2.5 GPa. The pressures would be lower and higher than this range if only olivine or orthopyroxene, respectively, were left in the source. We assume that the picrite mare glasses are primary magmas derived by relatively low degrees of melting [47]. The source rocks in our model were derived as olivine-orthopyroxene cumulates from a shallow magma ocean and then carried downward to higher pressure in the interior during the overtum. For pressures greater than about $0.5-0.6$ $\mathrm{GPa}$, the olivine-orthopyroxene cotectic lies very 
close to the plagioclase-orthopyroxene join and the cumulates deposited from these liquids would have orthopyroxene $\gg$ olivine. It follows, therefore, that olivine cannot be the sole unmelted phase in the source, which means that the mare glasses were derived from an orthopyroxene \pm olivine source, and must have been derived from depths corresponding to pressures of at least $2.0-2.5 \mathrm{GPa}(\sim 400-500$ $\mathrm{km}$ ).

If the mare basalts are not primary magmas but have undergone near-surface crystallization of olivine, then the estimated depths of generation are greater than the pressures of multi-saturation. This follows from the experimental observation that the orthopyroxene-olivine cotectic becomes more olivine-normative with increasing pressure. If the mare basalts are collections of polybaric melts as proposed by Longhi [48], then the apparent pressures of multi-saturation represent a mean pressure of generation, i.e., melts were generated at pressures both above and below 2-2.5 GPa.

As a source for mare volcanism, melting at the top of the mixed layer must occur at low enough pressure for melt to be buoyant relative to solid and at high enough pressure to satisfy the multi-saturation contraint discussed above. Melting at the top of the mixed layer must begin within 500-600 Myr of the overturn since the oldest high- $\mathrm{TiO}_{2}$ mare basalts appeared at least 3.9 Myr ago [6]. Our results summarized in Table 1 show that core radioactivity of 10 times bulk earth values, core radius of $550 \mathrm{~km}$, and the highest compositional density gradient satisfy this constraint as the top of the mixed layer intersects the solidus after about 500 Myr. But models with smaller bulk radioactivities do not. The models with bulk radioactivities of 5 times bulk earth values generate melts only at more than one Gyr after core formation. Models with small compositional density gradients have similar difficulties. For the same bulk radioactivity and mantle viscosity, the models with $0.3 \%, 0.6 \%$ and $0.9 \%$ density change per $100 \mathrm{~km}$ generate melts at $1000 \mathrm{Myr}, 636 \mathrm{Myr}$ and $507 \mathrm{Myr}$, respectively. It is clear that the low gradient case cannot produce melts in the time required and the intermediate gradient case is only marginally acceptable. Only the highest gradient case clearly satisfies the known age constraints on mare volcanism. The same is true for the model with a $475 \mathrm{~km}$ core radius. This would, however, require higher heating rates than the model with a $550 \mathrm{~km}$ radius core. In models that produce meling at the top of the mixed layer in 500-600 $\mathrm{Myr}$, the pressure of melting is in the range of 3-3.5 GPa (see Table 1).

Any model for the generation of high- $\mathrm{TiO}_{2}$ mare basalts from such depths faces a serious obstacle if high $\mathrm{TiO}_{2}$ mare basalt liquids are neutrally buoyant with respect to an olivine-rich mantle in the $2-2.5$ GPa pressure range $[4,49]$. High $\mathrm{TiO}_{2}$ mare basalt liquids that are more dense than an olivine and/or orthopyroxene residue at higher pressures should therefore sink rather than rise toward the surface to be erupted. One solution to this dilemma is to suppose that high $\mathrm{TiO}_{2}$ mare liquids do not wet the grain boundaries of olivine and/or pyroxene. In fact Toramaru and Fujii [50] have presented experimental evidence that terrestrial ocean floor basalt liquid does not wet the grain boundaries of enstatite in mantle peridotite. In dry experiments in the olivineorthopyroxene-plagioclase system, melt was also excluded from pyroxene grain triple junctions [51] Because the degree of melt connectivity depends critically on the composition of the melt, we cannot conclude that this behavior applies to high- $\mathrm{TiO}_{2}$ mare liquids in the lunar mantle. But if mare basalts liquids are not interconnected for small degrees of melting, melt would initially be trapped along grain junctions containing orthopyroxene. Such melt would be carried upward by upwelling mantle even though the melt is not buoyant relative to the mantle in which it resides.

An alternate solution [3] is that the rate of mantle upwelling exceeds the sinking rate of negatively buoyant melt. Near solidus melt crytallizes as it descends along its adiabat. Only above the neutral buoyancy depth can melt segregate into descrete bodies in which it becomes effectively isolated from the mantle. If this model is correct, the high- $\mathrm{TiO}_{2}$ melts are products of polybaric melting and the apparent pressure of multisaturation is the pressure below which the melt becomes positively buoyant.

\section{Summary}

This paper has explored the chemical and thermal consequences of an internal evolution model ac- 
$\because r$ heating

core. In

sne mixed

tring is in

$\mathrm{iO}_{2}$ mare

iostacle if

$\because$ buoyant

the $2-2.5$

are basalt

re and/or

es should

surface to

is to sup-

it wet the

ne. In fact

verimental

ialt liquid

nstatite in

se olivine-

was also

zions [51]

$y$ depends

we cannot

high- $\mathrm{TiO}_{2}$

tare basalts

degrees of

along grain

melt would

ven though

mantle in

e of mantle negatively ilizes as it the neutral to descrete olated from : high-TiO $1 \mathrm{~g}$ and the he pressure , buoyant.

and thermal model ac- counting for the possible role of chemical buoyancy and differences in radioactive element content resulting from the crystallization of the luthar magma ocean. Rayleigh-Taylor instability causes the dense ilmenite-rich cumulate layer and underlying Fe-rich cumulates that form near the end of magma ocean solidifation to sink toward the center of the Moon. After this overturn, radioacitve heating within the ilmenite-rich cumulate core heats the overlying mantle, causing the development of a heated, convectively mixed layer above the core-mantle boundary that eventually becomes thick enough and hot enough to melt. This deep high-pressure melting, as required by the chemisty of the mare basalts, occurs after a reasonable time interval to explain the onset of mare basalt volcanism if the content of radioactive elements in the core is about 10 times that of the bulk Moon (taken to be equivalent to bulk earth values) and the chemical density gradients above the core are comparable to values that would be expected if a minimal amount of mixing occurred during large scale overturn of the initially unstably stratified lunar interior.

Regardless of details implied by particular model parameters, gravitational overturn driven by the high density of magma ocean ilmenite-bearing cumulates should concentrate high- $\mathrm{TiO}_{2}$ mare basalt sources, and probably a significant fraction of radioactive heating, toward the center of the Moon. This will have important implications for both the thermal evolution of the Moon and for mare basalt genesis.

\section{Acknowledgements}

The paper benefitted from the reviews of $J$. Longhi, G. Ryder, and C.K. Shearer. The research reported was supported by NASA grants NAGW1928 and NAGW-3613 [CL].

\section{References}

[1] P.C. Hess and E.M. Parmentier, Overturn of magma ocean ilmenite cumulate layer: implications for lunar thermal and magmatic evolution, Lunar Planet. Sci. 25, 541-542, 1994.

[2] P.C. Hess and E.M. Parmentier, Overturn of magma ocean ilmenite cumulate layer: implications for lunar thermal and magmatic evolution, Lunar Planet. Sci. 24, 651, 1993.
[3] P.C. Hess, Diapirism and the origin of high $\mathrm{TiO}_{2}$ mare glasses, Gcophys. Res. Lell. 18, 2069-20172, 1991.

[4] J. Delano, Pristine lunar glasses: Criteria, data and implications, J. Cieophys. Res. 91, 201-213, 1980

[5] J.W. [Dclanu, Buoyancy driven melt segregation in the Earth's moon, Proc. L unar Planet. Sci. Conf. 20, 3-12, 1990.

[6] L.E. Nyquist and ( . Y. Shih, The isotopic record of lunar volcanism, Geochim. Cosmochim. Acta 56, 2213-2234, 1992

[7] D.L. Turcotte, F.A. Cooke and R.J. Willeman, Parameterized convection within the Moon and the terrestrial planets, Proc. Lunar Planct. Sci. Conf. 10, 2375-2392, 1979.

[8] G. Schubert, P. Cassen and R.E. Young, Subsolidus convective cooling histories of terrestrial plancts. Icarus 38, 192211,1979

[9] S.C. Solomon and I. Chaikin, Thermal expansion and thermal stress in the Moon and terrestrial planets: Clues to early thermal history. Proc. Lunar Sci. Conf. 7, 3229-3243, 1976.

[10] S.C. Solomon, On the early thermal state of the Moon, in: Origin of the Moon, W.K. Hartman, R.J. Phillips and G.J. Taylor, eds., pp. 435-452, Lunar Planet. Inst., Houston, TX, 1986.

[11] S. Mueller, G.J. Taylor and R. Phillips, Lunar composition: A geophysical and petrological synthesis, J. Geophys. Res. 93, 6338-6352, 1988.

[12] R.L. Kirk and D.J. Stevenson, The competition between thermal contraction and differentiation in the stress history of the Moon, J. Geophys. Res. 94, 12,133-12,144, 1989.

[13] J.O. Dickey, P. L. Bender, J.E. Faller, X.X. Newhall, R.L. Ricklefs, J.G. Ries, P.J. Shelus, C. Veillet, A.L. Whipple, J.R. Wiant, J.G. Williams and C.F. Yoder, Lunar laser ranging. A continuing legacy of the Apollo program, Science 265, 482-490, 1994.

[14] S.C. Solomon and J. Longhi, Magma oceanography: 1. Thermal evolution, Proc. Lunar Planet. Sci. Conf. 8, 583-599, 1977.

[15] F. Herbert, Time dependent lunar density models, Proc. Lunar Planet. Sci. Conf. 11, 2015-2030, 1980.

[16] J.W. Minear, The lunar magma ocean: A transient lunar phenomenom? Proc. Lunar Planet. Sci. Conf. 11, 1941-1955, 1980.

[17] S.R. Taylor, Planetary Science: A Lunar Perspective, Lunar Planet. Inst., Houston, TX, 1982.

[18] J.A. Wood, Moon over Mauna Loa: A review of the hypothesis of the formation of the Earth's Moon, in: Origin of the Moon, W.K. Hartman, R.J. Phillips and G.J. Taylor, eds., pp. 17-56, Lunar Planet. Inst., Houston, TX, 1986.

[19] F.J. Spera, Lunar miagmas transport phenomena, Geochim. Cosmochim. Acta 56, 2253-2266, 1992.

[20] W.B. Tonks and H.J. Melosh, The physics of crystal settling and suspension in a turbulent magma ocean, in: Origin of the Earth, Newsom and Jones, eds., pp. 151-174, 1990.

[21] D. Walker and W.S. Kieffer, Xenolith digestion in large magma bodies. Proc. Lunar and Planet. Sci. Conf. 15(2), J. Geophys. Res. 90, C585-590, 1985.

[22] W.C. Phinney, Lunar anorthosites, the equilibrium melts and the bulk moon. Proc. Lunar Planet. Sci. 21, 29-50, 1991. 
[23] P.C. Hess, M.J. Ruthertort and H.W. Camphell, Ilmenitc crystallization in non-marc basalt: (ienesis of KREEP and high-Ti mare basalt, Proc. L unir Planel. Sci Conf. 9, 705$724,1978$.

[24] (;. Ryder, Lunar ferroan anorthosites and mate basalt sources The mixed connection, Geophys. Res. Lett. 18, 2065-2068, 1991.

[25] A.E. Ringwood and S.1:. Kessoll, A dynamic model for mare basalt petrogenesis. Proc. Lunar Planct. Sci. Conf. 7, 1697 1722,1976

[26] A.G.W. Cameron and W. Benz, The origin of the Moon and the Single Impact Hypothesis, IV, Icarus 92, 204-216, 1991.

[27] P.H. Warren, The bulk moon $\mathrm{MgO} / \mathrm{FeO}$ ratio: a highlands perspective, in: Origin of the Moon, W.K. Hartman, R.J. Phillips and G.J. Taylor, eds., pp. 278-310, Lunar Planet. Inst., Houston, TX, 1986.

[28] A.E. Ringwood, S. Seifen and H. Wanke, Komatiite component in Apollo 10 highland breccias: Implications for the nickel-cobalt systematics and the bulk composition of the Moon, Earth Planet. Sci. Lett. 81, 105-117, 1987.

[29] J.H. Jones and J.W. Delano, A three component model for the bulk composition of the Moon, Geochim. Cosmochim. Acta 53, 513-527, 1989

[30] H.St.C. O'Neill, The origin of the Moon and the early history of the Earth -A chemical model, Part 1, The Moon, Geochim. Cosmochim. Acta 55, 1135-1157, 1991.

[31] G.A. Snyder, L.A. Taylor and C.R. Neal, A chemical mode for generating sources of mare basalts: Combined equilibrium and fractional crystallization of the lunar magmasphere, Geochim. Cosmochim. Acta 56, 3809-3823, 1992.

[32] P.C. Hess, M.J. Rutherford, R.N. Guillemette, F.J. Ryerson and H.A. Tuchfeld, Residual products of fractional crystallization of lunar magma: An experimental study, Proc. Lunar Planet. Sci. Conf. 6, 895-909, 1975.

(33) M.D. Norman and G. Ryder, A summary of the petrology and geochemistry of pristine highland rocks, Proc. Lunar Planet. Sci. Conf. 10, 531-559, 1979.

[34] P. Ulmer, The dependence of the $\mathrm{Fe}^{+2}-\mathrm{Mg}$ cation partitioning between olivine and basaltic liquid on pressure, temperature and composition. An experimental study to $30 \mathrm{kbar}$, Contrib. Mineral. Petrol. 101, 261-273, 1989.

[35] P.C. Hess, Petrogenesis of lunar troctolites, J. Geophys. Res $99,19,083-19,093,1994$.

[36] P.H. Warren, Lunar anorthosites and the magma ocean hypothesis: importance of $\mathrm{FeO}$ enrichment in the parent magmas, Am. Mineral. 75, 46-58, 1990.
[37] L.L. Hood, Geophysical constraints on the lunar interiur, in Origins of the Moon, W.K Lartman, R.J. Phillips and (i.t laylor, eds., pp. 301-410, Lunitr Planet. Inst., Ifouslon, TX 1986.

[38] PH. Warren and J.T. Wasson, Origin of KRLI:P, Res Geophys. Space Phys. 17, 73-88, 1979

[39] R.W. Griffiths and 1.H. Camphell, Stirring and structure in mantle starting plumes, Earth Planct Sci. Lell. $90,60-78$, 1990.

[40] C.K. Shearer and J.J. Papike, Basaltic magnuatism on the Moon: a perspective from volcanic picritic glass beads, Geochim. Cosmochim. Acta 57, 4875-4812, 1993.

[41] G.K. Batchelor, An Introduction to Fluid Dynamics, Canbridge Univ. Press, Cambridge, 1967.

[42] G. Hirth and D.L. Kohlstedt, Experimental constraints on the dynamics of the partially molten upper mantle: deformation in the diffusion creep regime, J. Geophys. Res. $I(\%), 1981$ 2001,1995

[43] I.D. MacGregor, The system $\mathrm{MgO}-\mathrm{SiO}_{2}-\mathrm{TiO}_{2}$ and its bearing on the distribution of $\mathrm{TiO}_{2}$ in basalts, Am. J. Sci. 267A, 342-363, 1969

[44] S.A. Morse, Basalts and Phase Diagrams, Springer, New York, NY, 1980

[45] R.A. Lange and I.S.E. Carmichael, Densities of $\mathrm{Na}_{2} \mathrm{O}-$ $\mathrm{K}_{2} \mathrm{O}-\mathrm{CaO}-\mathrm{MgO}-\mathrm{FeO}-\mathrm{Fe}_{2} \mathrm{O}_{3}-\mathrm{Al}_{2} \mathrm{O}_{3}-\mathrm{TiO}_{2}-\mathrm{SiO}_{2}$ liq uids: New measurements and derived partial molar properties, Geochim Cosmochim Acta 51, 2931-2946, 1987.

[46] J. Longhi, Experimental petrology and petrogenesis of marc volcanics, Geochim. Cosmochim. Acta 56, 2235-2252, 1992.

[47] S.S. Hughes, J.W. Delano and R.A. Schmitt, Petrogenetic modeling of 74220 high- $\mathrm{TiO}_{2}$ orange volcanic glasses and the Apollo 11 and 17 high Ti-mare basalt, Proc. Lunar Planet. Sci. Conf. 19, 175-188, 1989.

[48] J. Longhi, Origin of picritic green glass magmas by polybaric fusion, Proc. Lunar Planet. Sci. Conf. 22, 343-354, 1992.

[49] C.B. Agee and S. Circone, Crystal-liquid density inversions in high-TiO, lunar basalt, Lunar Planet. Sci. 25, 5-6, 1995.

[50] A. Toramaru and N. Fujii, Connectivity of melt phase in a partially molten peridotite, J. Geophys. Res. 91, 9239-9252, 1986.

[51] N. Fujii, K. Osamura and E. Takahashi, Effect of water saturation on the distribution of partial melt in the olivinepyroxene-plagioclase system, J. Geophys. Res. 91, 92539259, 1986

[52] J.A. Whitehead, Fluid models of geological hotspots, Ann Rev. Fluid Mech. 20, 61-87, 1988. 
"xrior. in

and (i.).

sun. TX

$\therefore P . R e v$

:ucture in

$60-78$,

:I on the

ss beads,

ics, Cam-

ints on the tormation

. $0,1981-$

d its bearici. $267 \mathrm{~A}$,

Iger, New

if $\mathrm{Na}_{2} \mathrm{O}-$ $\mathrm{SiO}_{2}$ liq:ar propery87.

is of mare 252, 1992 . etrogenetic jasses and roc. Lunar

y polybaric $4,1992$.

inversions 5-6, 1995 phase in a +239-9252

t of water he olivine91, 9253spots, Ann.

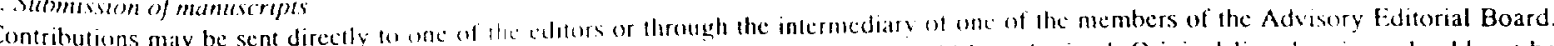

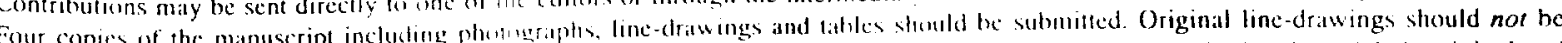

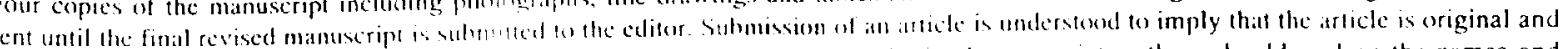

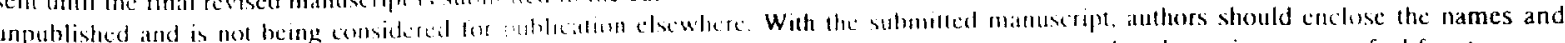

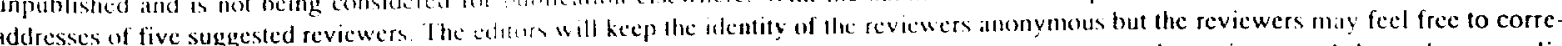
spond directly with the athors it they so de sme. The responshility for direct communication betwen the reviewer and the author must lie with the reviewer. With a view to increasing the speed of publication authors are encouraged to revise within 6 weeks after receiving their reviews. At the editors' discretion am revision received after this time limit ma be regarded as a new submission that is subject to handling as a new paper. Upon acspence of an artick by the journal, the author(s) will be asked to transfer the copyright of the

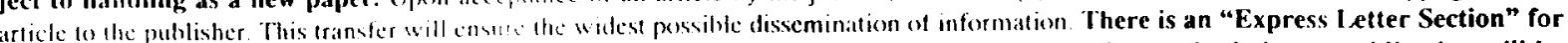
short, original papers. The maximum permissible length is 5 journal pages and the tocal time from submission to publication will be ca. 3 months. Please refer to the announcement in this issue for more details. (a) Submessiom of electronic text ln order to publish the paper as quickly as possible, after acceptance, atuthors are encouraged to submit lic final text also on a diskette. Please sec the full instructions in the last issue of this volunic. Author are encouraged to ensure that the diskette version and the hardcopy are identical - discrepancies can lead to publication of the wrong version. *only the title page and alsstract should be provided on diskette with the original submission; this will be used when $\mathfrak{t}^{-}$-mailing potential referees.

2. Lengrh of papers

THE MAXIMUM PERMISSIBLE LENGIH OF PAPERS IS IS PRINTED JOURNAL PAGES. A WORD COUNT MUST BE PROVIDED ON THE TITLE PAGE OF MANUSCRIPTS. THERE ARE NO PAGE CHARGES.

3. Language

Manuscripts should be written in English only. and except for very short papers thcy should include a brief abstract.

4. Preparasion of the text

(a) The manuscript should be prepared on a word processor and printed with double spacing and wide margins and include an abstract of not more than 500 words.

(b) Authors should use IUGS terminology. The use of S.I. units is also recommended.

(c) The title page should include the names of the authors, and their affiliation addresses and fax and e-mail numbers. In the case of more than one author, please indicate to whom the correspondence should be addressed.

5. References

References should be limited to the minimum number necessary for citation of pertinent material. As a guide an average of 4 references per printed page can be used, with a maximum of $\mathbf{5 0}$ references per article. References to internal reports, etc., are to be avoided (The statement "personal communication" with publication date in the text is preferable.)

References to the literature should stricly follow the journal's format: the references should be numbered in the order in which they are cited, and given in numerical sequence in the reference list at the end of the manuscript. The numbers should appear in the text in the appropriate places using numerals in square brackets on the line. In the reference list, periodicals [1], books [2], multi-author books [3] and proceedings [4], should be cited in accordance with the following examples:

1 I.M. Villa, J.C. Huneke and G.J. Wasserburg, "Ar recoil losses and presolar ages in Allende inclusions, Earth Planet. Sci. Lett. 63, 1-12, 1983.

2 I.S.E. Carmichael, F.J. Turner and J. Verhoogen, Igneous Petrology, 739 pp., McGraw-Hill, New York, N.Y., 1974.

3 S.R. Taylor, Chemical composition and evolution of the continental crust: the rare earth element evidence, in: The Earth, its Origin, Structurc and Evolution, M.W. McElhinney, ed., pp. 2-44, Academic Press, London, 1978.

4 V.T. Bowen, H.D. Livingston and J.C. Burke, Distribution of transuranium nuclides in sediment and biota of the North Atlantic Ocean, in: Transuranium Elements in the Environment, IAEA Symp. Proc., pp. 107-120, 1976.

Abbreviations for titles of journals should follow the system used in the "Bibliographic Guide for Editors and Authors" published in 1974 by the American Chemical Society, Washington, D.C.

6. Tables and illustrations

Tables should be compiled on separate sheets. A title should be provided for each table and they should be referred to in the text. Tables can Tabies should be compiled on separate sheets. A title should be provided normal page-size reproduction of such tables should also be included in the manuscript. Efforts should be made to make the size of the tables correspond 10 the format of the journal (max. $15 \times 20 \mathrm{~cm}$ ).

(a) All illustrations should be numbered consecutively and referred to in the text.

(b) Illustrations should be lettered throughout, the size of the lettering being appropriate to that of the illustrations, but taking into acount the possible need for reduction in size. The page format of the journal should be considered in designing the illustrations. All illustrations must be originals, in the form of glossy figures or laser prints. Each illustration must be accompanied by a photocopy.

(c) Photographs must be of good quality, printed on glossy paper.

(d) Figure captions should be supplied on a separate sheet.

(e) Colour figures can be accepted providing the reproduction costs are met by the author. Please consult the publisher for further information.

7. Proofs

To achieve the high speed of publication, no proofs are sent to the authors. Manuscripts should therefore be prepared with the greatest possible care, and the submission of negatives for tabular material is encouraged. Galley proofs may occasionally be obtained by making a special request to the editor, with the understanding that this implies delay in publication.

\section{Fiffy free reprints}

Fifty reprints of each article published are supplied free of charge. A form for ordering extra reprints will be sent to the corresponding author on receipt of the accepted manuscript by the publisher. 


\section{Physics and Evolution of the Earth's Interior}

\section{Series now complete!}

\section{Interior \\ Edited by J. Leliwa -Kopystynski and R. Tolsseyre}

Constitution of the Earth's

Physics and Evolution of the Earth's Interior Volume 1

1984 xii +368 pages

Dfl. 267.00 (US $\$ 152.50$ )

ISBN 0-444-99646-X

Selsmic Wave Propagation In the Earth

\section{By A. Hanyga}

Physics and Evolution of the Earth's Interior Volume 2

1985 xvi + 478 pages Dfl. 318.00 (US $\$ 181.75$ )

ISBN 0-444-99611-7

Continuum Theories in

Solid Earth Physics

Edited by $\boldsymbol{A}$. Teisseyre

Physics and Evolution of the Earth's Interior Volume 3

1986 xiv + 566 pages

Dfl. 376.00 (US $\$ 214.75$ )

ISBN 0-444-99569-2

Gravity and Low - Frequency Geodynamics

Edited by R. Telsseyre

Physics and Evolution of the Earth's Interior Volume 4

$1989 \times$ Xi + 478 pages

Ofl. 313.00 (US $\$ 178.75$ )

ISBN 0-444-98908-0
This six-volume series deals with the most important problems of solid Earth physics and presents the most general theories describing contemporary dynamical processes and the Earth's evolution.

Six-Volume Set

DIl. 1350.00 (US $\$ 771.00$ ) ISBN 0-444-81750-6

Evolution of the Earth and Other Planetary Bodles

Edited by R. Telsseyre, J. Leliwa-Kopystynski and B. Lang

Physics and Evolution of the Earth's Interior Volume 5

"This volume is a competently constructed up-to-date and detailed summary of planetary evolution. It is for the planetary scientist above other fields; in this category, the book deserves a wide readership simply for its breadth of coverage. Researchers in other fields will also find this a book worth dipping into, and whole lecture courses could be based around its comtents. It appears that the initial wish to discuss planetary evolution across the solar system has resulted in an intelligent, advanced level treatise that will become widely relerenced itself."

\section{Earth-Science Reviews}

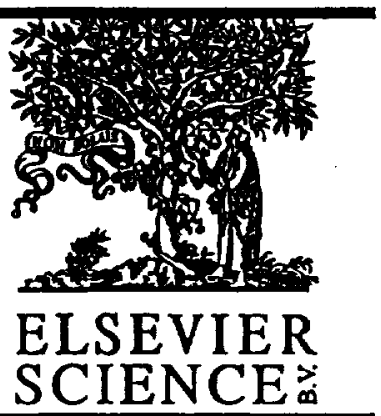

1992 xii + 584 pages Dff. 370.00 (US $\$ 211.50$ ) ISBN 0-444-98833-5

Dynamics of the Earth's Evolution

Edited by R. Teisseyre,

L. Czechowskl and

J. Leliwa-Kopystynski

Physics and Evolution of the Earth's Interior Volume 6

This sixth volume in the monograph series Physics and Evolution of the Earth's Interior presents the problems of the mature evolution of the Earth's interior. It provides

comprehensive coverage of the present state of the mantle convection theory. The relations between paleomagnetism, plate tectonics and mantle convection theory are discussed. A more general view of the evolution based on the thermodynamics of irreversible processes is also given.

1993480 pages

Dfi. 350.00 (US $\$ 200.00$ )

ISBN 0-444-98662-6

\section{ELSEVIER SCIENCE B.V.}

P.O. Box 1930

1000 BX Amsterdam

The Netherlands

\section{P.O. Box 945}

Madison Square Station New York, NY 10160-0757

The Dutch Guilder (Dfl.) prices quoted apply worldwide. US \$ prices quoted may be subject to exchange rate fluctuations. Customers in the European Community should add the appropriate VAT rate applicable in their country to the price. 